\title{
Plausible role of ICT in transforming medical education
}

Prof. J.U.Weerasinghe BDS, MS, PhD

Professor in Oral \& Maxillofacial Surgery, Faculty of Dental Sciences, University of Peradeniya Visiting Professor, Post Graduate Institute of Medicine, University of Colombo

Executive Editor, Sri Lanka Journal of Bio-medical Informatics

E-Mail address: juw@pdn.ac.lk

Sri Lanka Journal of Bio-Medical Informatics 2011;2(3):84-85

DOI: http://dx.doi.org/10.4038/sljbmi.v2i3.3859

Significant changes in principles of education worldwide to strengthen student centred learning have been observed in the past few years. E-learning or ICT-enabled learning has made an impact in this regard. Various curriculum reforms that take place in the undergraduate and postgraduate courses reveal that ICT has already influenced the domain of medical education.

Several major challenges have been identified to accomplish usage of ICT for medical education which include introduction of e-learning methods for undergraduate teaching, encouraging postgraduate students to use web resources and empowering clinicians with ICT facilitated medical knowledge for better delivery of patient care.

In relation to undergraduate teaching, e-learning could be used to aid the teaching of physical skills. Tools such as 'multimedia enhanced virtual patient' allow the learner to develop skills other than from the bedside ${ }^{(1)}$. It is also possible to teach the skills of diagnostic reasoning and patient management and developing attitudes through interactivity. Introduction of Learning Management Systems (LMS) allows the experts to create content, the learner to access it, and the administrator to monitor the process. This process has transformed the teacher's role from disseminator to facilitator $^{(2)}$.

The two original articles in this issue discuss research carried out to assess the ICT skills of medical and dental undergraduates in Sri Lanka and focus on the need and preparation of the student population to receive ICT based education methods.

In a different perspective, postgraduate medical education focuses on offering specialty training at registrar and senior registrar levels. Unlike undergraduates, PG trainees will have to work under several trainers in different centres. A trainee in a remote area without adequate resources will have to reach for virtual resources such as e-libraries and virtual communities such as e-discussion groups $^{(3)}$.

Close cooperation between ICT experts and clinicians will help develop various learning resources which would help both society and clinicians. The current practice article in this issue discusses the Sri Lankan scenario in this context.

Finally, clinicians living in a global village concept will have to share knowledge and skills across the globe with the help of experts in ICT fields. The lead article in this Issue explicitly discusses this issue of the use of Multimedia Integrated Learning Framework for Medical Education that has already been tested between Sri Lanka and Japan.

Therefore, with the incorporation of ICT which will play a positive role in transforming the medial education principles and encourage collaborative learning 
opportunities, clinicians of tomorrow will be equipped with an adequate ICT enabled knowledge when offering treatment for patients; most of whom will be knowledgeable about their condition and options for treatment.

\section{References}

1. Choules AP. The use of e-learning in medical education: a review of the current situation. Postgrad Med J. 2007; 83: 212-216.

doi: $10.1136 /$ pgmj.2006.054189

2. Ruiz JG, Mintzer MJ, Leipzig RM, The Impact of e-learning in medical education. Acad Med. 2006; 81(3): 207-12. PMID:16501260

3. Karsenti T, Charlin B. Information and communication technologies (ICT) in medical education and practice: The major challenges. International Journal of Technologies in Higher Education 2008; 5(2): 68-81 